\title{
A CIDADE COMO ESPAÇO PÚBLICO: uma interpretação pautada na fala dos jovens
}

\author{
Prof $^{\mathrm{a}}$. Dr ${ }^{\mathrm{a}}$. Clarice Cassab \\ Curso de Geografia da Universidade Federal de Juiz de Fora \\ Rua José Lourenço Kelmer, s/n - CEP: 36036-330 - Juiz de Fora (MG), Brasil \\ Tel.: (+ 55 32) 21023101 - clarice.torres@ufjf.edu.br
}

\section{RESUMO}

A proposta do trabalho é apresentar algumas reflexões produzidas a partir de pesquisa junto a jovens urbanos, moradores da cidade de Juiz de Fora - Zona da Mata Mineira. Nela foram entrevistados jovens, moradores de quatro bairros considerados pobres da cidade, visando identificar quais os sentidos que estes davam à cidade. É o resultado desse diálogo que o texto pretende apresentar. Seu objetivo, portanto, é o de apresentar e debater quais as relações que os jovens constroem com a cidade e como compreendem e apreendem a cidade com o intuito de pensar a cidade como espaço público, como espaço da pluralidade e, portanto, como primeira experiência da política. Reforçando, com isso, a importância de seu uso e apropriação.

Palavras-chave: Cidade, jovem, espaço público.

\begin{abstract}
The proposed article presents some reflections produced from research with young urban residents in the city of Juiz de Fora - Zona da Mata Mineira. In it were interviewed young in four poor urban neighborhoods in order to identify which senses they gave to the city. It is the result of this dialogue that the text intends to present. Its objective, therefore, is to present and discuss what the relations that the young people constructs with the city and as they understand and apprehend the city with the intention to think the city as public space, as space of the plurality and, therefore, as first experience of the politics. Strengthening, with this, the importance of its use and appropriation.
\end{abstract}

Key words:City, public space, young.

\section{RESUMEN}

El artículo propuesto presenta algunas reflejos producidas a partir de la investigación con jóvenes habitantes de la ciudad de Juiz de Fora - Zona da Mata Mineira. En él se entrevistó a adultos jóvenes en cuatro barrios pobres de la ciudad con el fin de identificar qué sentidos se dio de la ciudad. Es el resultado de este diálogo que el texto se prepone presentar. Su objetivo, por lo tanto, es presente y discutir cuáles son las relaciones que establecen con la ciudad y la forma de entender y tomar la ciudad a fin de considerar la ciudad como espacio público, como espacio de la pluralidad y, por lo tanto, como primera experiencia de la política. Consolidando, con el, la importancia de su uso y la apropiación.

Palabras clave: Jóvenes, ciudad, espacio público.

\section{INTRODUÇÃO}

A proposta do trabalho é apresentar algumas reflexões produzidas a partir de pesquisa junto a jovens urbanos, moradores da cidade de Juiz de Fora - Zona da Mata Mineira. Tal pesquisa faz parte de um projeto maior de identificação e mapeamento dos trajetos dos jovens na cidade em sua busca por lazer, trabalho e ensino. A intenção é identificar quais os usos que os jovens fazem da cidade. Por onde andam, como andam e como se apropriam das cidades em seus trajetos? Para chegar a este objetivo, contudo, foi preciso trabalhar qual o sentido de cidade que possuíam. Ou seja: o que é cidade, o que ela deveria oferecer e o que mudariam nela. É o resultado desse diálogo que ora se apresenta nesse texto. Seu objetivo, portanto, é o de indicar e debater quais as relações que os jovens constroem com a cidade - como compreendem e apreendem a cidade visando contribuir para a compreensão da importância de entender a cidade como espaço público e, consequentemente, da política.

Para tanto o texto se organiza de maneira a evidenciar as falas dos jovens no que toca suas representações sobre cidade, seus bairros de moradia e sobre a rua de maneira a produzir uma reflexão sobre a centralidade que a cidade possui como espaço de constituição do sujeito "jovem 
pobre urbano". Entender, portanto, a cidade - e em especial a cidade capitalista - e suas formas de organização, como elemento na constituição dos próprios jovens urbanos, sujeitos deste estudo.

Para isso foram entrevistados quatro grupos de jovens, entre 15 e 18 anos, residentes em bairros considerados pobres de Juiz de Fora. A saber: Santa Cândida, Dom Bosco, São Pedro e Granjas Bethânia. A opção por realizar as entrevistas em grupo se explica a partir de uma maior descontração entre eles, o que levou, em muitos momentos, com que a resposta de um estimulasse ou complementasse a do outro, havendo, portanto, maior troca e enriquecimento dos dados.

O trabalho se desenvolveu através da metodologia de pesquisa qualitativa, em entrevistas semi-estruturadas organizadas a partir do eixo da relação dos jovens com a cidade. Nesse estudo, a entrevista semi-estruturada foi realizada mediante a mistura de perguntas fechadas e abertas que conduziram a pesquisadora ao longo de todo o processo de trabalho. Nesse tipo de entrevista são selecionados a priori alguns tópicos sem, contudo, elaborar perguntas fechadas condizentes aos tópicos. Além de coletar os dados referentes às questões norteadoras da pesquisa, também se procurou observar as manifestações dos entrevistados diante das perguntas e dos temas propostos.

Pretendeu-se compreender de que maneira os jovens representam e vivem a cidade e, para tanto, foi perguntado como os jovens descreveriam seu bairro e sua cidade; como era a relação do bairro com o restante da cidade; se circulavam por outros bairros da cidade e o que havia na rua que lhes interessavam. Após as entrevistas as falas foram classificadas em grupos de respostas, cada um referente a um determinado padrão de resposta em relação ao assunto perguntado. As falas aqui apresentadas serão ilustrativas dos principais agrupamentos de respostas dados pelos jovens quando das entrevistas. Para fins deste artigo serão tratadas apenas as pertinentes ao tema: representação da cidade.

Justifica-se a necessidade dessa discussão na medida em que o artigo assenta-se na premissa de que o espaço é elemento constituinte da sociedade, portanto, instância social. Sendo ele instância, compõe os próprios sujeitos e suas práticas. Ou seja, entender o jovem urbano significa, necessariamente, compreender os sentidos que estes sujeitos dão a cidade bem como as formas de uso que fazem dela. Ao término espera-se apontar para alguns aspectos considerados fundamentais para que se possa decifrar a relação indissociável entre o sujeito desse estudo e a cidade.

\section{A CIDADE COMO ESPAÇO PÚBLICO: a centralidade do circular}

Para Lefebvre (2008) as contradições do espaço são resultantes do conteúdo prático e social de uma sociedade determinada no bojo da qual contradições e conflitos se manifestam. Tendo isso em vista o autor propõe pensar as práticas sociais de produção e reprodução do espaço a partir de três dimensões: práticas espaciais (percebido), representações do espaço (concebido) e espaços de representação (vivido). A primeira se constituiria pela relação entre as ações e os objetos, portanto, entre o homem e os suportes materiais que estão no espaço. Já o espaço concebido refere-se às formas de conceber e representar o espaço (leis, códigos, posturas, normas, mapas, planos, entre outros). Para o autor, as representações do espaço propiciam os espaços dominantes. Estes teriam um caráter abstrato, servindo para homogeneizar e naturalizar as diferenças. $\mathrm{O}$ espaço vivido é percebido através das representações e práticas espaciais cotidianas. E se, de um lado, é subjugado ao espaço concebido, de outro, é nele que Lefebvre situa a possibilidade de transgressão, da criatividade e da subversão.

O espaço abstrato é o espaço onde prevalece valor de troca, já o espaço vivido é o espaço onde prevalece o valor de uso. No movimento de transformação do espaço em mercadoria, o espaço abstrato se impõe sobre o espaço vivido. Nesse processo, o espaço concebido tem papel fundamental na medida em que a esfera econômica e o Estado, por meio das representações do espaço, pressionam o espaço da vida cotidiana. Há no pensamento de Lefebvre um árduo embate que se realiza no e pelo espaço, entre valor de uso e valor de troca, entre as pressões exercidas pelo espaço abstrato e as resistências do espaço concreto. 
Nesta leitura, o espaço se constitui da e pela relação da/com a sociedade. (Re) afirmar que o espaço é social é reforçar que a análise geográfica só é possível através da dialética espaço-sociedade. Consequentemente não é possível pensar o espaço apenas como elemento impassível e neutro sobre o qual se desenrolam as práticas sociais. Incorporando a noção de produção é possível superar a ideia de espaço como palco da ação humana iluminando a dimensão social do espaço produzido por uma sociedade diferenciada (LEFEBVRE, 1981; SOJA, 1980; SANTOS, 1996).

Apresentado como produto de um processo de relações sociais, o espaço torna-se humano não apenas porque o homem o habita, mas porque o produz - daí seu caráter social, sendo, no entanto, um produto desigual e contraditório assim como a sociedade que o produziu com seu trabalho. Produto histórico, o espaço é ativo e dinâmico condicionando e sendo condicionado pela sociedade. Nas palavras de Moreira (1986, p.123) "o espaço é a sociedade territorialmente construída", sendo ele mesmo uma estrutura social. Também para Santos (1996), o espaço caracteriza-se por ser um híbrido, dado a inseparabilidade entre o natural e o artificial. Sendo a união dos sistemas naturais e históricos materiais, o espaço seria formado pelo "conjunto indissociável do substrato físico, natural ou artificial e mais o seu uso ou, em outras palavras, a base técnica e mais as práticas sociais, isto é, uma combinação de técnica e de política" (SANTOS, 1999, p. 5).

Nesse sentido, o espaço se constitui como a síntese, permanentemente provisória, entre o conteúdo social e as formas sociais. Ele é a forma e a vida que a anima, um conjunto de valores sempre em mutação. Daí a impossibilidade de se pensar o espaço desassociado da sociedade. Não existe espaço sem homem, pois

é a sociedade, isto é, o homem, que anima as formas espaciais, atribuindo-lhe um conteúdo, uma vida. Só a vida é passível desse processo infinito que vai do passado ao futuro, só ela tem o poder de tudo transformar amplamente. Tudo o que não retira sua significação desse comércio com o homem é incapaz de um movimento próprio, não pode participar de nenhum movimento contraditório, de nenhuma dialética (SANTOS, 1996, p.88).

O caminho inverso também é possível. Pensar o homem, não apenas como mais um membro de uma coletividade, integrando um grupo homogêneo, mas como ser social, é pensar seu espaço. E nesse sentido propõe-se, no âmbito desse artigo, pensar a cidade como o espaço que compõem o jovem urbano.

Essa questão ganha relevância no âmbito desse artigo na medida em que se entende que a conquista da cidade representa uma das possibilidades de construção da ação e da política para os jovens pobres urbanos. O deslocar-se pela cidade, o aventurar-se no desconhecido, a percepção das relações e contradições expressas no espaço, o reconhecimento das diferenças e das desigualdades, tudo isso significa experimentar a própria cidade, dando-lhe sentido através da ação.

Mas o que é cidade para esses jovens e que imagem eles constroem dela? As falas apresentadas ao longo do texto ilustram quatro grupos de respostas. No primeiro, a cidade é definida apenas como sendo o lugar onde se vive. Assim se expressam, por exemplo, dois jovens ao afirmarem que "a cidade é onde a gente mora" ou ainda, "é onde eu vivo".

No segundo grupo, a cidade é associada a determinadas funções bem como ao sentido de aglomeração. Define um jovem "que cidade é área de comércio", mas também "é um lugar onde tem moradores, comércio, mercado, tem festas, shows, ruas, carros". O jovem sintetiza ao afirmar que "a cidade é tudo que está ao nosso redor - os prédios, as casas".

Um terceiro sentido atribuído à cidade é o que se refere à velocidade. A cidade é o espaço do movimento, onde tudo acontece de forma veloz. Assim, nos diz uma jovem que a cidade "é um lugar de muito movimento". E por essa razão a "cidade é um outro jeito de vida. É mais corrido para os trabalhadores". Na fala define-se com clareza para quem esse tempo é corrido: para os trabalhadores. A identificação do tempo é do o tempo para e do trabalho. Mas a cidade não é só o tempo do trabalho. É também "o lugar onde você vê mais mulheres bonitas" e o "lugar de ter lazer".

Mercator - volume 9, número 20, 2010: set./dez. 
Um último grupo de respostas reúne os jovens para os quais a cidade se constitui como "espaço de diversidade" e também o "lugar onde vivemos e convivemos com várias pessoas" e, por essa razão torna-se "local onde exercemos nossa cidadania nos relacionando com as pessoas". Nesse sentido, a cidade é "um lugar formado por um grupo de pessoas, ou seja, cidadãos. Onde encontramos muitos pontos interessantes em que conhecemos. É um lugar onde existem direitos e deveres". Nessas falas encontra-se o quarto sentido dado à cidade. A cidade é vista, por esses jovens, como um espaço de trocas e convivências.

Para os jovens residentes em São Pedro, essa dimensão é expressa em todas as falas. Como a de D. que diz:

Muita gente reclama que quer morar no centro, mas em São Pedro, se você quiser dar uma respirada, você tem a universidade. Assim, todo mundo quer morar no centro. Mas, às vezes, você não pensa que morando no Centro você não tem sossego. Eu acho que São Pedro é um bairro bom justamente pela sua diversidade. Eu tenho amigos que são muito mais simples, até financeiramente, em questão de estudo. Mas eu também tenho amigos que são muito mais ricos que eu, que moram em loteamentos fechados. Disso eu gosto em São Pedro.

A possibilidade de conviver com diferentes pessoas, os "amigos mais simples" e os "muito mais ricos", para o jovem, lhe proporcionaria uma experiência positiva. Sennett (1988) afirma que civilidade seria o ato de tratar os outros como estranhos e diferentes sem, contudo, deixar de estabelecer relações de convivência. Para o autor, a civilidade abre a possibilidade do diálogo sendo na cidade onde se materializa e ganha forma, pois é nela onde se dá o encontro dos estranhos e dos diferentes. Conforme Barbosa (1999, p.133),

A geografia pública da cidade começa a ser delineada quando o desejo de viver com o(s) outro(s) se torna uma prática comum e ganha o abrigo institucional necessário. Assim, a cidade se configura, por excelência, como um espaço de encontro entre diferentes e desconhecidos, contribuindo para que os seres humanos se tornem mais ricos de experiências no seio da vida societária.

Assim, para os jovens entrevistados, a cidade é representada como o lugar onde vivem, se caracterizando pela aglomeração e diversidade que, por sua vez dão o sentido de um tempo veloz, no qual tudo ocorre com rapidez, desde a circulação dos carros, pessoas, até acontecimentos. Contudo, também é o lugar do prazer e do lazer; o lugar onde se convive com outros, com o diverso, o diferente, abrindo, dessa forma, a possibilidade da política.

A política representa o meio pelo qual os membros de uma comunidade internalizam seus compromissos para com os demais, se constituindo como cidadãos, "pois no centro da política jaz a preocupação com o mundo, não com o homem - com um mundo" (ARENDT, 2008:158). Mas se é certo que a política é a condição humana, ela somente é possível pela existência da pluralidade, na medida em que ela reserva um duplo aspecto de igualdade e diferença. A igualdade permite que os homens se entendam entre si e façam planos para o futuro. No entanto, é a diferença que, ainda segundo a autora, possibilita o discurso e a ação, tendo a ação, por seu turno, a capacidade de criar permanências. Se não fossem diferentes, os homens não necessitariam do discurso ou da ação para se fazerem compreender (ARENDT, 2003). É dessa forma que, para Arendt, a diferença é vista como positiva, na medida em que "a política diz respeito à coexistência e associação de homens diferentes. Os homens se organizam politicamente segundo certos atributos comuns essenciais existentes em, ou abstraídos de, um absoluto caos de diferenças" (ARENDT, 2008:145).

$\mathrm{Na}$ diferença não cabe a hierarquização, uma vez que ela deve ser compreendida no sentido de alteridade, o que, por sua vez, apenas ocorre quando há interações, trocas, contato entre grupos diferentes. $\mathrm{O}$ que significa afirmar que a diferença se realiza quando confrontada com outra identidade, portanto, na troca e no contato. Existir socialmente é ser percebido como diferente e nesse sentido a diferença pode ser compreendida no terreno da atribuição do status da cidadania. 
No geral, quando se perguntou se saíam muito de seus bairros, os jovens afirmaram que sim justificando sua resposta pelo fato de que sair permitiria ter contado com outras coisas, realidades e pessoas, que não encontrariam em seus bairros. Esse é o tipo de resposta dada, por exemplo, por Fe., morador de Santa Cândida, ao dizer que "ficar num só lugar, ficar só aqui não vai adiantar nada; não vai ter amizade, não vai conhecer gente diferente". Sair de seu bairro significaria a oportunidade de ter contato com o diverso e de conhecer novas pessoas.

Colocar-se em movimento é fazer uso da cidade. É nesse sentido que os passos moldam espaços, tornando o ato de caminhar pareça "encontrar uma primeira definição como espaço de enunciação" (CERTEAU, 1990, p. 177). Estar na rua significa o encontro, nela ocorre a mistura sem a qual não é possível a vida urbana.

Assim, a possibilidade de usufruir da cidade como conjunto, como espaço público, significa a necessidade de romper barreiras impostas pela desigualdade sócio-espacial. Estar na rua é mais do que apenas pensá-la como local de passagem e circulação. Estar na rua significa circular pela cidade, colocando em evidência sua presença, criando e recriando espaços e dando-lhes sentido a partir da sua ação.

Não estar na rua é negar a própria vida urbana, a civilidade e a política sendo, portanto, a afirmação da segregação e da separação que imobiliza e despolitiza. É, portanto, dessa forma, que o espaço, e a cidade em particular, não pode ser compreendido como algo sem vida ou apenas o substrato da ação humana. Ao contrário, é parte integrante das ações sociais e, portanto, do próprio sujeito em questão - o jovem urbano pobre. Dessa forma, espaço e ação estão intrinsecamente associados, já que o espaço contém o movimento (SANTOS, 1991).

Diante disso, o que os levariam a sair de casa? As respostas foram agrupadas pelos seguintes motivos: 1) família e amigos; 2) emprego; 3 ) lazer e movimento. Em grande medida, esses jovens circulam pelos bairros onde moram familiares e/ou namorados(as). Os bairros freqüentados são, na sua grande maioria, próximos do seu de origem e semelhantes socioeconomicamente. Isso porque reconhecem as diferenças existentes entre seus bairros e o restante da cidade. Todos os jovens nos quatro bairros pesquisados identificam a existência de diferenças no que toca a ausência de serviços e equipamentos, nos hábitos, jeitos e aparências daqueles que vivem nos distintos bairros e no que se refere a imagem que o restante da cidade tem de seus bairros.

Dessa forma se expressa um jovem morador de Dom Bosco, ao dizer que seu "bairro não faz parte da cidade" pois ele seria "muito diferente". Mesma imagem construída por outro jovem, residente em Santa Cândida, ao afirmar: "Meu bairro parece outro mundo, o jeito de se vestir das pessoas no centro da cidade é diferente, o jeito de falar". Também seus bairros se diferenciam do restante da cidade devido à ausência de equipamentos e, no caso de Granjas Bethânia, a grande distância em relação ao centro da cidade. Dentre os jovens que sinalizaram nesta direção há, entre eles, certa sensação de isolamento em relação à cidade, pois em seu bairro "não tem nenhuma diversão. Não tem nada. Não tem uma praça, não tem uma sorveteria para tomar um sorvete, não tem forma nenhuma para se divertir. A gente acaba tendo que ir para outro lugar". Questionado sobre o porquê dessa situação, um dos jovens respondeu: "Eu acho também que é desprezo por ser um bairro tão longe assim do centro". As falas apontam a condição periférica de bairro, no entanto, invertendo a lógica. É como se o bairro não tivesse equipamentos urbanos pelo simples fato de ser distante. Esquece, talvez, que outros bairros também distantes do centro possuem esses equipamentos.

Por fim, um outro aspecto que diferenciaria seu bairro dos demais da cidade é a imagem de violência que o bairro possui. Contudo, esta imagem não seria compartilhada da mesma forma no conjunto da cidade. $\mathrm{O}$ bairro poderia ser visto de distintas maneiras dependendo do lugar no qual o observador se encontra; "se for um bairro mais central, Santa Cândida é muito perigoso. Têm uma má imagem de São Benedito e Vila Alpina. Mas se a gente descer lá embaixo, os perigosos somos nós. Quanto mais alto, mais perigoso para eles. Agora, bairro vizinho, nada a ver, não, todo mundo sobe, todo mundo desce". Santa Cândida, situado no alto de um morro, próximo ao centro

Mercator - volume 9, número 20, 2010: set./dez. 
da cidade, é tomado, de forma geral, como um bairro perigoso. A jovem, contudo, salienta que essa visão depende de onde se está. Assim, para os bairros mais centrais, ou bairros "de baixo", a imagem é essa. Mas nos bairros vizinhos a Santa Cândida, aqueles que "vivem a mesma realidade", essa imagem não se realiza. No entanto, afirma essa jovem e outros também residentes no bairro, que a imagem geral que se tem "é de briga" e de que "aqui é violento demais".

Se de um lado a rua, para esses jovens, é algo atraente onde é possível ter acesso a coisas novas, encontrar amigos e familiares, paquerar e se divertir buscar emprego, de outro as condições para estarem e circularem por ela são significativamente restritas. Isso porque, a circulação desses jovens, em grande medida, ser reduz ao seu bairro e entorno pois evitam ir a bairros de características distintas do seu já que se sentem constrangidos.

A dimensão positiva da diferença parece não se aplicar aos jovens pobres. Para eles a diferença é tratada como negatividade. Ser diferente significa ser invisível. Por essa razão, seu circular ruidoso pela cidade, sua forma de se vestir ou se expressar, sua fala, seus gostos e tantas outras estratégias de afirmação e mobilização desses sujeitos, aparecem como elementos de restrição ao uso da cidade.

Em suas falas os jovens entrevistados expressam o entendimento da existência de lugares distintos nos quais podem ou não circular. Em muitos casos, essa restrição não se dá pelo uso da força física, mas pelo constrangimento ou, como afirma Pierre Bourdieu, por uma violência simbólica que estigmatiza os jovens pobres e restringe seus usos na e da cidade. É o que parece estar por trás da fala de We. Que afirma só freqüentar seu bairro já que não gosta de "ficar no bairro de outras pessoas". Ou quando foi perguntado se utilizavam os dois shoppings existentes na cidade: o Santa Cruz, localizado no Centro, e o Independência. O primeiro é freqüentemente visitado por eles, sendo conhecido na cidade por atender um público cuja renda é mais baixa. Os jovens disseram ir ao Santa Cruz para ver o movimento, as modas e as garotas e garotos. Já o shopping Independência atende um público de renda média a alta. S. nunca foi a esse shopping, pois lá "tudo é caro". R. parece concordar e ainda observa que "lá é para rico, não é para nós". Essa foi a resposta padrão entre todos os entrevistados quando questionados sobre o interesse de irem ao Independência shopping.

Embora, de um lado reconheçam que "a cidade deveria ter lazer para todos os gostos", de outro, identificam os mecanismos de constrangimento, restrição e distinção territorial aos quais estão submetidos. Em sua experiência cotidiana na e pela cidade percebem que, na realidade, privilegiase e tolera-se o lazer de alguns jovens, não de todos. B. exemplifica: "Olha as brigas na rave e no baile funk. Se é no baile funk, logo eles interditam, porque é de pobre, do pessoal do morro. Esse preconceito é por causa da renda".

Diante desta representação negativa os jovens evitam o circular e buscam identificar em seus bairros elementos de segurança e proteção, estes, em grande medida definidos pelas relações de afetividade que constroem com o bairro ao longo de suas vidas. Em uma das falas, um das jovens diz:

Fui nascida e criada aqui, minha mãe também, não vejo como tão violento como dizem, nunca aconteceu nada comigo, não sei se é porque eu sou do bairro. Minha irmã, uma vez, estava com uma amiga lá no São Mateus, aí um cara foi assaltar e só assaltou a amiga dela, não levou nada dela. A gente acha que o cara deve ser aqui do Chapadão - quando viu que era ela, não roubou, entendeu? Mas eu vejo como um bairro bom.

A fala da jovem sinaliza, de um lado, a visão positiva que tem do bairro, já que foi lá que nasceu e se criou. Também mostra a sensação de segurança e proteção por estar no seu bairro de origem, explicitando os vínculos afetivos e de solidariedade existentes no lugar. Assim, quando o assaltante age, não rouba aquela que ele reconhece como sendo também moradora do bairro. É em seus próprios bairros que se sentem seguros e confortados. Em seus bairros estariam entre iguais, não vivenciando na pele e cotidianamente os mecanismos de restrição, distinção e desigualdade a que estão submetidos. Neles, se sentem salvos. 
Castro $(2004$, p.84) pondera que "para os jovens pobres esta errância está permeada de uma vigilância constante realizada pela repressão e pelo constrangimento do aparato policial, tornandose parte do cenário de humilhação e fortalecimento de estereótipos". Dessa maneira ainda que esses jovens possam se sentir seduzidos pelas possibilidades que a cidade oferece seus espaços de circulação são limitados e reduzidos.

J.S. ao falar como percebe a cidade diz que "tem lugar que só entra pessoa 'rica' e uma pessoa pobre é excluída daquilo. Assim quando um rico vai num lugar que é dos mais pobres eles são recebidos como uma pessoa qualquer e se sentem bem com aquilo". Fato também percebido pela jovem W.P. que, quando perguntada sobre como via a cidade, afirmava como "a cidade é dividida", pois “(...) em locais que os custos para se divertir é alto provavelmente só os ricos freqüentam. Pessoas que não tem muita condição moram em locais diferentes dos que tem. Os ricos moram em condomínios ou então em áreas nobres da cidade".

A cidade aparece, para estes jovens como fragmentada cujos pedaços pertencem a uns e não a outros. E esta organização desigual parece empurrar os jovens pobres cada vez mais para longe das possibilidades de apropriação efetiva da cidade. A estratégia capitalista de dominação do espaço reduz os moradores da cidade à função de compradores de espaço. $\mathrm{O}$ espaço urbano possui valor de troca o que faz com que sua apropriação se dê nos marcos da propriedade privada e do mercado. Nessa perspectiva os habitantes da cidade perdem a dimensão da cidade em sua totalidade. A cidade se torna fragmentada pelos espaços possíveis de serem "comprados". Ou como disse o jovem, por "bairros que são de outras pessoas".

Ao subordinar o espaço, transformando-o em mercadoria, o mercado impõe cada vez mais limites às condições e possibilidades de seu uso. O flanar, o lazer, os corpos e os passos dos jovens pobres estão mais limitados aos seus bairros ou a locais vigiados, normatizados e privados. Os jovens pobres não vivem a cidade da mesma forma que os demais jovens. Ao contrário, parece que a esses jovens não está reservado viver a cidade como espaço público em seu sentido mais amplo. Suas ações são limitadas pelas desigualdades e pelas restrições que são impostas. Seu direito à cidade é ínfimo ou inexistente. A cidade, portanto, para eles, não se realiza como obra na medida em que seu uso é pequeno e atravessado por restrições concretas e simbólicas. $\mathrm{O}$ espaço não se realiza como totalidade.

O que é corroborado quando se pensa nos mecanismos de distinção espacial evidentes nas cidades. Segundo Villaça (1998), na formação das cidades brasileiras o que se observa é a existência das mais variadas formas de segregação, desde aquelas produzidas pela etnia, nacionalidade até as de classe.

A reunião desses jovens pobres pelas ruas e seu movimento pela cidade, seja na busca de lazer ou mesmo na procura de emprego, é visto como potencialmente perigosa. A ocupação da cidade pelos jovens só é tolerada dentro dos limites da ordem imposta pelos adultos, o que significa de forma disciplinada, preferencialmente sozinhos e restrita a determinados bairros. Esses jovens têm sua circulação controlada e tolhida. O que se agrava quando a lógica da distinção territorial impõe a jovens pobres o não direito de estarem em muitas partes da cidade.

De forma geral, portanto, as falas dos jovens sinalizam para uma situação de restrita mobilidade pela cidade devido às condições objetivas, como o custo de transporte, violência policial ou as condições simbólicas, como as manifestadas por expressões como "não se sentir bem em outros bairros". Restrições estas que, por sua vez, reduzem as condições de experiência e vivência das inúmeras possibilidades abertas pela cidade. Pois, se é certo que a cidade é palco de inúmeras fragmentações e desigualdades também é verdade que ela possui elementos que apontam para o questionamento e a ruptura de suas próprias contradições.

Contudo, ao permanecerem confinados em seus bairros ou em bairros de características semelhantes, esses jovens internalizam e naturalizam sua condição de jovens pobres, inclusive reproduzindo em seus discursos e práticas os mecanismos de desigualdade, distinção e diferenciação

Mercator - volume 9, número 20, 2010: set./dez. 
a que são submetidos. Embora reconheçam a cidade como espaço de aglomeração, de diversidade e de troca, assim como identificam os limites de seus próprios bairros, esses jovens pouco estão na cidade.

Enfatiza-se a importância dos jovens vivenciarem a cidade pois acredita-se ser ela espaço público por excelência na medida em que é espaço da pluralidade e primeira grande experiência da política. Ou, nas palavras de Santos (1996), "para o homem comum, o Mundo, o mundo concreto, imediato, é a cidade" (SANTOS, 1996:82). É nela onde o mundo e os homens se movem mais. Talvez por isso alguns dos jovens tenham associado à cidade a imagem da velocidade.

É nela que a co-presença permite ensinar a diferença. Uma das jovens afirmou ser a cidade "o local onde exercemos nossa cidadania nos relacionando com as pessoas", enquanto outro dizia ser a cidade "o lugar onde vivemos e convivemos com várias pessoas". É por esses motivos que a cidade "é o lugar da educação e da reeducação. Quanto maior a cidade, mais vasta e densa a copresença e também maiores os laços e aprendizados" (SANTOS, 1996:83).

Viver a cidade estando de fato nela, construindo e ampliando seus usos, desnaturalizando as forças que promovem a distinção territorial desses jovens, ampliando a co-existência e, conseqüentemente, a política, identificando os vínculos entre as representações sobre os jovens pobres, sobre o espaço e sobre as práticas que promovem os arranjos espaciais da cidade é condição sine qua non para a ação.

\section{CONSIDERAÇÕES FINAIS}

É possível pensar a cidade como objeto de apropriações diferenciadas e é nessa lógica que se processa o afastamento daquele que não é desejável. A posição dos jovens pobres no tecido urbano reflete as relações sociais de tipo desigual, que resultam em diferentes capacidades de apropriação do espaço urbano, representando "a concentração dos diversos segmentos sociais em territórios bem definidos e a institucionalização da inferioridade, da desclassificação e da imobilidade das classes populares" (CARVALHO, 2004, p.10).

No processo de distinção espacial parece também estar em jogo a capacidade de apropriação do espaço urbano como sendo um espaço decisivo para a produção e reprodução da vida dos jovens. Por essa razão que a apropriação também é entendida como a possibilidade de se mover, possuir e agir. Apropriar-se remete à identificação com o espaço e, conseqüentemente, a possibilidade de sua transformação. Um espaço de que não se faz parte ou com o qual não se identifica, não é apropriado e conseqüentemente transformado.

O que se verifica é que, em muitas situações, os jovens pobres têm reduzida possibilidade de apropriação econômica, não podendo, com isso, intervir de maneira decisiva na estruturação do espaço urbano. Mais do que isso, suas possibilidades de apropriação sociocultural e psicossocial também são limitadas. É nesse sentido que ao se falar em distinção espacial também se está falando da não possibilidade de apropriação do espaço da cidade

A conseqüência disso é, dentre outros aspectos, a pouca visibilidade desses jovens. Sujeitos invisíveis, sua cidadania não é nem sequer definida pelo consumo, já que não consomem a cidade ou, quando o fazem, o fazem de maneira periférica. Sem direito à cidade, esses jovens vivem cotidianamente situações de constrangimento e de distinção espacial. Suas diferenças são negativizadas, sua circulação é restringida ou mesmo negada, sendo comumente constrangidos pelos estigmas que carregam no corpo, pelo simples fato de serem jovens pobres e moradores de bairros periféricos. Esses jovens parecem não ter futuro.

Contudo, se a pesquisa mostrou, de um lado, as dificuldades vivenciadas pelos jovens pobres de terem acesso à cidade como obra, sentido pleno do direito à cidade, conforme Henri Lefevbre, suas falas também apontaram para o reconhecimento da existência dessas desigualdades. Estes jovens sabem e reconhecem sua condição de jovem pobre, afastados do direito ao uso da cidade. 
É este horizonte que nos permite pensar outro devir afirmando o circular, o colocar-se na rua, a ação como expressões da política e possibilidades que precisam ser abertas a esses jovens. Daí a ênfase que se dá à rua, ao circular, ao viver e experimentar a cidade. A cidade entendida como o primeiro contato com o público. Nela, eles podem construir relações, identificar as desigualdades, positivar as diferenças, desnaturalizar sua condição subalterna. A cidade, portanto, como um espaço da política - entendida como resultante da relação entre homens. É preciso, efetivamente, tornar a rua e a cidade um espaço de todos e um espaço de encontro. Inclusive para os jovens urbanos pobres.

\section{REFERÊNCIA BIBLIOGRÁFICA}

ARENDT, Hannah. A condição humana. Rio de Janeiro: Forense universitária, 2003.

ARENDT, Hannah. A promessa da política. Rio de Janeiro: DIFEL, 2008.

BARBOSA, J. L. O ordenamento territorial urbano na era da acumulação globalizada. In. SANTOS, M. ET all (org). Território, territórios: ensaios sobre o ordenamento territorial. Rio de Janeiro: Lamparina, 1999. BOURDIEU, P. O poder simbólico. São Paulo: Bertrand Brasil, 2005.

CORRÊA, R. L. O espaço urbano. São Paulo: Ática, 1987.

CARVALHO, Ináia Maria Moreira de. "Metrópoles e condições sociais". Anais do VIII Congresso Luso-afro-brasileiro de Ciências Sociais. Coimbra: 2004.

CASTRO, Lucia Rabello. A aventura urbana: crianças e jovens no Rio de Janeiro. Rio de Janeiro: 7Letras, 2004.

CERTEAU, Michel. A invenção do cotidiano. Petrópolis: Vozes, 1990.

LEFEBVRE, H. La Production de l'espace. Paris: 2éme édition, 1981.

LEFEBVRE, H. O direito à cidade. São Paulo: Centauro, 2001.

LEFEBVRE, H. Espaço e política. Belo Horizonte: EdUFMG, 2008.

MARQUES, Eduardo \& TORRES, Haroldo. São Paulo: segregação, pobreza e desigualdades sociais. São Paulo: SENAC, 2005.

MOREIRA, R. Uma gestão democrática do espaço para uma sociedade de homens livres. Natureza e sociedade como principio da ecologia política e novo paradigma histórico. Espaço e sociedade, São Paulo, ano 2, n.2, 1986.

SANTOS, Milton. A natureza do espaço: técnica e tempo, razão e emoção. São Paulo, HUCITEC, 1996.

SANTOS, Milton. Metamorfose do espaço habitado: fundamentos teóricos e metodológicos da geografia. São Paulo: HUCITEC, 1991.

SANTOS, Milton. Guerra dos lugares. São Paulo: Folha de São Paulo, Caderno Mais, 8/8/1999.

SENNETT, R. O declínio do homem público. São Paulo: Companhia das Letras, 1988.

SOJA, E. W. Geografias pós-modernas: a reafirmação do espaço na teoria social crítica. Rio de Janeiro: J. Zahar, 1993.

VILLAÇA, Flávio. Espaço intra-urbano no Brasil. São Paulo: Nobel, 1998.

Trabalho enviado em setembro de 2010

Trabalho aceito em dezembro de 2010

Mercator - volume 9, número 20, 2010: set./dez. 